\title{
USO DA IMPEDÂNCIA NA DETERMINAÇÃO DO VOLUME GLOBULAR DAS ESPÉCIES FELINA, EQUINA E BOVINA
}

\section{Impedance method for packed cell volume determination in feline, equine and bovine species}

\author{
VIEIRA, R.F.C. ${ }^{1}$; VIOL, M.A. ${ }^{2}$; BARBOSA, T.S. ${ }^{3}$; SOEIRO, C.S. ${ }^{2}$; BOMFIM, S.R.M. ${ }^{4}$; \\ CIARLINI, P.C. ${ }^{4}$
}

\footnotetext{
${ }^{1}$ Curso de Pós-graduação em Ciências Veterinárias - UFPR, Bolsista CNPq

${ }^{2}$ Residente de Diagnóstico Veterinário - UNESP Araçatuba

${ }^{3}$ Curso de Pós-graduação em Ciência Animal - UNESP Araçatuba

${ }^{3}$ Departamento de Clínica, Cirurgia e Reprodução Animal - UNESP Araçatuba
}

Endereço para correspondência: Paulo Cesar Cialini - ciarlini@fmva.unesp.br

\section{RESUMO}

Objetivou-se determinar a correlação entre os valores de volume globular (VG) das espécies felina, equina e bovina com dois diferentes métodos: por impedância e pelo método de Strumia. Para tal, amostras de sangue de 70 gatos, 80 cavalos e 77 bois foram analisadas. Os valores de VG, em ambos os métodos, foram obtidos num período compreendido entre 20 - 120 minutos após a colheita. Os valores de VG obtidos pelos métodos de Strumia e impedância apresentaram correlação $(r=0,98$ gatos, $r=0,98$ cavalos e $r=0,96$ bois) extremamente significante $(p<0,001)$ para as três espécies. Concluiu-se que o valor do VG determinado por impedância revelou-se confiável e é recomendado para o uso clínico nas espécies felina, equina e bovina.

Palavras-chave: hematócrito, Strumia, volume globular, impedância

\section{ABSTRACT}

The aim of this study was to determinate the correlation of packed cell volume (PCV) between cats, horses and cows with two different methods: by impedance and by the Strumia method. For this purpose, blood samples from 70 cats, 80 horses and 77 cows were analyzed. The PCV data, in both methods, were determined at $20-120$ minutes after blood collection. The PCV data obtained by Strumia and impedance methods $(r=$ 0.98 cats, $r=0.98$ horses and $r=0.96$ cows) were extremely significant $(p<0.0001)$ for the three species. In conclusion, the PCV data determined by impedance was reliable and it is recommended for clinical use in feline, equine and bovine species.

Key words: hematocrit, Strumia, packed cell volume, impedance.

\section{INTRODUÇÃO}

O Volume Globular (VG) ou hematócrito representa a medida da fração do volume sanguíneo que é ocupado pelos eritrócitos e expresso em porcentagem e é o parâmetro hematológico mais confiável que os clínicos dispõem para estimar o 
grau de anemia e eritrocitose (Jain, 1993). O método de Strumia (micro-hematócrito) (Strumia et al., 1954) é na atualidade o mais utilizado para a determinação do VG nos laboratórios clínicos veterinários de rotina. A adequada colheita e homogeneização da amostra, relação sangue/anticoagulante, o tempo e a força gravitacional de centrifugação são fundamentais para obtenção de valores precisos do VG (Jain, 1993). Os contadores hematológicos automáticos fornecem o valor do VG indiretamente, a partir da integração numérica do volume corpuscular médio (VCM) obtido por impedância dos eritrócitos. O princípio de contagem é baseado na variação de impedância utilizando o princípio de Coulter, gerada pelo impulso elétrico, oriundo da passagem das células através do micro-orifício calibrado (Weiss e Tvedten, 2004).

A necessidade de se obter resultados laboratoriais em pequenos volumes de amostras, em menor tempo e com menor custo tem estimulado os laboratórios veterinários a adotar aparelhos hematológicos automatizados. Os contadores hematológicos eletrônicos, inicialmente desenvolvidos para humanos, têm sido adaptados para animais que apresentam células sangüíneas com maior variabilidade morfométrica e morfológica, além de maior tendência para aglutinar do que o sangue humano (Roleff et al., 2007). A maioria desses equipamentos veterinários foi recentemente introduzida no mercado e necessitam de validação para diferentes espécies. Neste sentido, são escassos os estudos que avaliaram a correlação entre os valores de VG obtidos por impedância e método de Strumia (Strumia et al., 1954) para as espécies felina, equina e bovina (Dawson, et al., 2000; Dewhurst et al., 2003; Roleff et al., 2007; Weingand et al., 1992). Recentemente, Vieira et al. (2007) verificaram que existe uma boa correlação entre os métodos utilizando amostras de cães.
Considerando que os valores hematológicos de referência dos animais domésticos foram estabelecidos em sua maioria sem uso de equipamentos eletrônicos e objetivando orientar os clínicos veterinários que solicitam exames hematológicos em laboratórios automatizados, o presente estudo testou a hipótese de que os valores de VG das espécies felina, equina e bovina obtidos por impedância não diferem e apresentam uma boa correlação com os obtidos pelo clássico método de Strumia.

\section{MATERIAL E MÉTODOS}

Foram examinadas amostras de sangue de 70 gatos, 80 cavalos e 77 bois de diferentes raças, faixas etárias e sexo, enviadas ao Laboratório Clínico do Hospital Veterinário "Luiz Quintiliano de Oliveira", Universidade Estadual Paulista (UNESP), campus de Araçatuba, durante o período de Janeiro a Junho de 2007.

Todas as amostras foram acondicionadas em tubos contendo ácido etilenodiamino tetra-acético sódico - EDTA (1,8mg / $\mathrm{mL}$ sangue), mantidas em temperatura ambiente $\left(20-25^{\circ} \mathrm{C}\right)$ e processadas entre 20 e 120 minutos póscolheita. Amostras com fibrina e microcoágulos foram excluídas do estudo.

O VG de todas as amostras foi determinado pelo método de impedância com aparelho eletrônico (Contador de Sangue Automatizado ABC Vet ${ }^{\circledR}, A B X$ Diagnostics, Montpellier, França) previamente calibrado para as espécies estudadas, seguindo o procedimento operacional padrão do fabricante. Simultaneamente, o VG de cada amostra foi determinado pelo método de Strumia (Strumia et al., 1954), utilizando-se centrifuga de micro-hematócrito (Centrífuga Hematócrita Micro Spin ${ }^{\circledR} 1000$, Centribio, China), tubos capilares de $1,0 \mathrm{~mm}$ de diâmetro interno sem anticoagulante (Tubo Capilar PERFECTA ${ }^{\circledR}$, PERFECTA Ind. e Com. de Lâminas de Vidro LTDA., São 
Paulo, Brasil) submetidos a cinco minutos de centrifugação (11.089 g). Todas as análises foram realizadas em duplicata, conforme recomendações para estudos envolvendo métodos comparativos (Jensen e Kjelgaard-Hansen, 2006).

Com auxílio do programa estatístico GraphPad Software Prism $^{\circledR}$, após a confirmação da homocedasticidade dos dados pelo teste de Bartlett e da normalidade pelo teste de KolmogorovSmirnov, calculou-se o coeficiente de correlação de Pearson e determinou-se a significância das diferenças entre os dois métodos pelo teste t pareado.

\section{RESULTADOS}

Observou-se valores para o VG dentro dos parâmetros normais e casos de eritrocitose nas três espécies avaliadas. As amostras de cavalos analisadas apresentaram ampla variação nos valores de VG, incluindo valores de acentuada anemia (Tabela 1).

Tabela 1 - Valores de volume globular (VG) obtidos por impedância (VG i) e pelo método de strumia (VGs) em sangue das espécies felina, equina e bovina [média \pm desvio padrão; amplitude (mínimo máximo); coeficiente de correlação de pearson (r)].

\begin{tabular}{|c|c|c|c|}
\hline Espécie & Felina & Eqüina & Bovina \\
\hline \multirow{2}{*}{ VG s (\%) } & $33,8 \pm 8,5^{a}$ & $32,7 \pm 7,3^{a}$ & $30,7 \pm 8,0^{a}$ \\
\hline & $(10-59)$ & $(13-51)$ & $(10-48)$ \\
\hline \multirow[b]{2}{*}{ VG i (\%) } & $35,4 \pm 9,3^{b}$ & $33,2 \pm 7,9^{b}$ & $29,2 \pm 7,9^{b}$ \\
\hline & $\begin{array}{l}(10,7- \\
60,70)\end{array}$ & $\begin{array}{c}(12,1- \\
55,1)\end{array}$ & $(8,8-47,5)$ \\
\hline $\begin{array}{c}V G s-V G \\
i(\%)\end{array}$ & $-4,54$ & $-1,15$ & 4,94 \\
\hline Correlação & $\begin{array}{c}r=0,98(p< \\
0,0001)\end{array}$ & $\begin{array}{r}r=0,98(p< \\
0,0001)\end{array}$ & $\begin{array}{c}\mathrm{r}=0,96(\mathrm{p}< \\
0,0001)\end{array}$ \\
\hline
\end{tabular}

* Letras não coincidentes na mesma coluna indicam diferença significativa.

Embora os dois métodos tenham apresentado alta correlação (Tabela 1), a média do VG diferiu nos gatos $(P<0,0001)$, nos cavalos $(P=0,0004)$ e nos bois $(P<$
0,0001). Os valores das diferenças entre a impedância e o método de Strumia variaram com a espécie (Figuras 1, 2 e 3), porém em média esta diferença foi inferior a $5 \%$ (Tabela 1).

\section{DISCUSSÃO}

Os achados obtidos neste estudo foram semelhantes aos encontrados por Roleff et al. (2007), que utilizaram a mesma metodologia em amostras das espécies felina e equina e aos de Vieira et al. (2007) e que verificaram uma boa correlação entre a determinação do VG por impedância e método de Strumia em cães. Dewhurst et al. (2003), observaram excelente correlacao do VG determinado por impedância utilizando dois aparelhos comerciais em amostras de cães e gatos. Becker et al. (2008), comparando aparelhos eletrônicos com diferentes tecnologias, obtiveram uma excelente correlação entre os metodos em amostras de cães e gatos.

Independentemente do valor de VG (normal, diminuído ou aumentado), a diferença entre os dois métodos não apresentou um padrão, sendo ora positiva ou negativa (Figuras 1, 2 e 3). Não obstante, os valores de VG obtidos por impedância tendem a ser superiores aos obtidos pelo método de Strumia nas espécies felina e equina. No entanto, em relação à espécie bovina, verificou-se 0 contrário. Provavelmente a característica de empilhamento dos eritrócitos (Rouleaux) comum às espécies felina e equina, possa contribuir para tal diferença.

A divergência de valores de VG obtidos entre os dois métodos foi, em média, inferior na espécie equina $(-1,15 \%)$ em relação à felina $(-4,54 \%)$ e bovina $(4,94 \%)$, provavelmente devido ao fato da anisocitose eritrocitária ser maior nestas duas espécies (Jain, 1993). Tais diferenças entre os valores de VG obtidos pelos dois métodos nas três espécies foram inferiores a $5 \%$, portanto uma variação dentro do que 


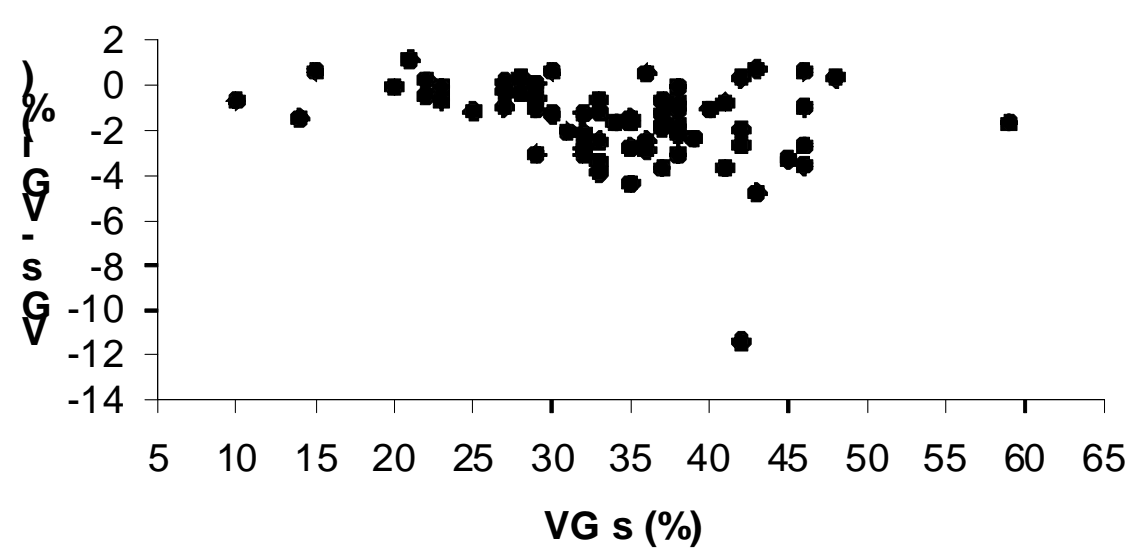

FIGURA 1 - Distribuição da diferença entre o valor do volume globular (VG) obtido por impedância (VG i) e pelo método de Strumia (VG s) na espécie felina.

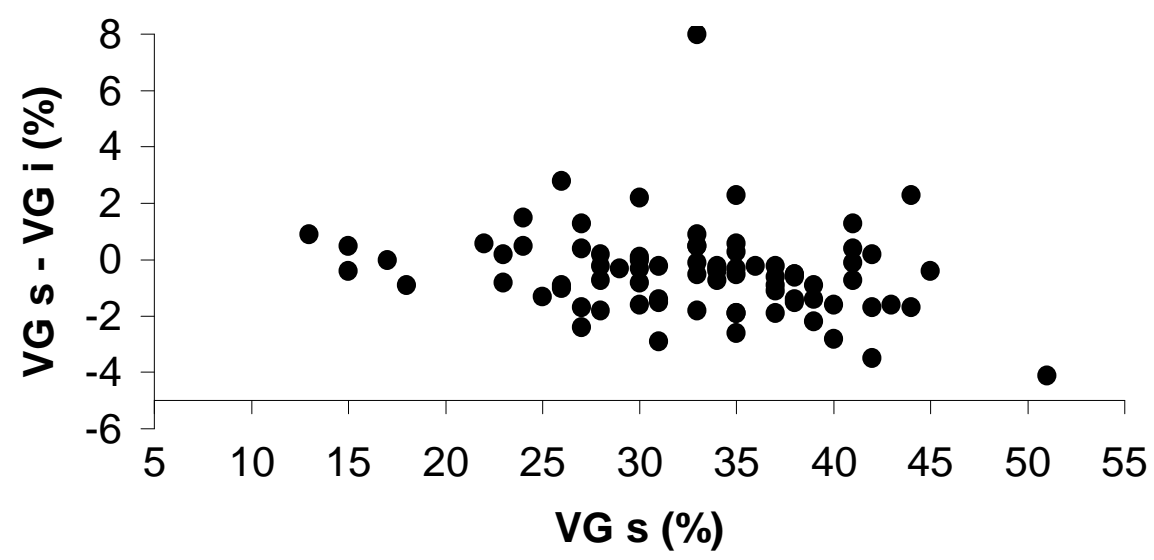

FIGURA 2 - Distribuição da diferença entre o valor do volume globular (VG) obtido por impedância (VG i) e pelo método de Strumia (VG s) na espécie equina.

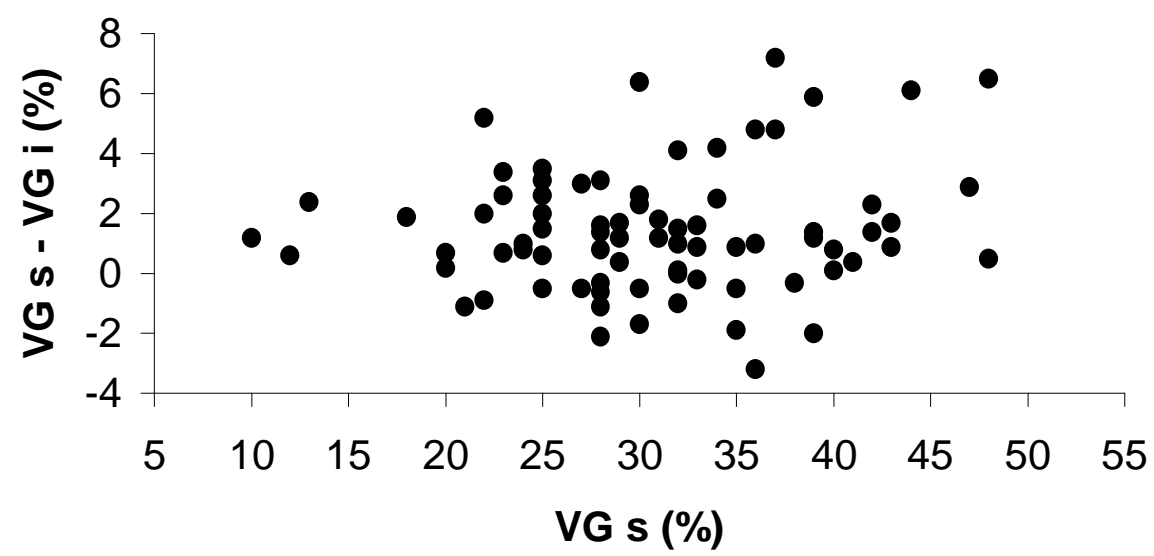

FIGURA 3 - Distribuição da diferença entre o valor do volume globular (VG) obtido por Impedância (VG i) e pelo método de Strumia (VG s) na espécie bovina. 
é clinicamente aceitável (Jensen e Kjelgaard-Hansen, 2006) e certamente não compromete 0 diagnóstico laboratorial. Considerando ainda que os dois métodos apresentaram uma alta correlação, concluise que os valores de VG obtidos por impedância podem ser utilizados com segurança tanto na avaliação clínica das discrasias eritrocitárias quanto em valores dentro da faixa de normalidade para as espécies felina, equina e bovina, mesmo na ausência de valores de referência obtidos com esta metodologia. Porém, para se obter maior sensibilidade diagnóstica tornase necessário o estabelecimento de valores hematológicos de referência que considere a metodologia adotada no laboratório.

\section{CONCLUSÃO}

O VG obtido por impedância apresenta boa correlação com 0 determinado pelo método de Strumia nas especies estudadas, podendo ser adequadamente utilizado pelos clínicos veterinários.

\section{REFERÊNCIAS}

BECKER,M.; MORITZ,A.; GIGER,U. Comparative clinical study of canine and feline total blood cell count results with seven in-clinic and two commercial laboratory hematology analyzers. Veterinary Clinical Pathology, California, v.37, n.4, p.373-384, 2008.

DAWSON,H.; HOFF,B.; GRIFT,E.; TVEDTEN,H.; SHOUKRI,M. Validation of the Coulter AcT Diff Hematology Analyzer for Analysis of Blood of
Common Domestic Animals. Veterinary Clinical Pathology, California, v.29, n.4, p.132-136, 2000.

DEWHURST,E.C.; CRAWFORD,E.; CUE,S.; DODKIN,S.; GERMAN,A.J.; PAPASOULIOTIS, K. Analysis of canine and feline haemograms using the VetScan HMT analyzer. Jornal of Small Animal Practioners, Inglaterra, v.44, n.10, p.443-448, 2003.

JAIN,N.C. Examination of the blood and bone marrow. In: JAIN,N.C. Essentials of Veterinary Hematology. 1.ed. Philadelphia: Lea \& Febiger, 1993, p.3-4.

JENSEN,A.L.; KJELGAARD-HANSEN,M. Method comparison in the clinical laboratory, Veterinary Clinical Pathology, California, v.35, n.3, p.276-286, 2006.

ROLEFF,S.; ARNDT,G.; BOTTEMA,B.; JUNKER,L.; GRABNER,A.; KOHN,B. Clinical evaluation of the CA530-VET hematology analyzer for use in veterinary practice. Veterinary Clinical Pathology, Califórnia, v.36, n.2, p.155-66, 2007.

STRUMIA, M.M.; SAMPLE, A.B.; HART, E.D. An improved microhematocrit method. American Journal of Clinical Pathology, Chicago, v.24, n.9, p.1016-1024, 1954.

VIEIRA,R.F.C.;

BARBOSA,T.S: MORINISHI,C.K. CIARLINI,P.C.; BOMFIM,S.R.M. Volume globular de cães determinado por impedância e método de microhematócrito (strumia). Acta Scientiae Veterinariae, Porto Alegre, v.35, n.2, p.433-435, 2007.

WEINGAND,K.W.; ODIOSO,L.W.; DAMERON,G.W.; LAYTART,M.J.; STITZEL,K.A. Hematology analyzer comparison: Ortho ELT-8/ds vs. Baker 9000 for healthy dogs, mice and rats. Veterinary Clinical Pathology, Califórnia, v.21, n.1, p.10-14, 1992.

WEISS,D.; TVEDTEN,H. The complete blood count and bone marrow examination: general comments and selected techniques. In: WILLARD,M.D.; TVEDTEN,H. Small Animal Clinical Diagnosis by Laboratory Methods. 4.ed. Missouri: Saunders, 2004, p.18-19. 